\title{
Osteoarthritis Related Pain: Which Procedure is the Optimal Choice?
}

\author{
Paolo Pedersini ${ }^{1 \star}$, Mark Donald Bishop ${ }^{2}$, Jorge Hugo Villafañe ${ }^{1}$
}

${ }^{1}$ IRCCS Fondazione Don Carlo Gnocchi, Milan, ITALY

${ }^{2}$ Department of Physical Therapy, University of Florida, USA

`Corresponding Author: pedersini93@gmail.com

Citation: Pedersini P, Bishop MD, Villafañe JH. Osteoarthritis Related Pain: Which Procedure is the Optimal Choice?. Electron J Gen Med. 2021;18(5):em305. https://doi.org/10.29333/ejgm/11014

\section{ARTICLE INFO}

Received: 9 Jan. 2021

Accepted: 17 Mar. 2021

\begin{abstract}
Osteoarthritis (OA) is not simply a matter of mechanical damage and several risk factors are involved in the manifestation of the OA phenotype. OA-related pain management needs a multidisciplinary approach involving various treatment options including nonpharmacological and pharmacological ones. Due to the low number of high-quality studies related to $O A$ related pain treatment, which conservative or non-conservative procedure should be chosen?
\end{abstract}

Keywords: osteoarthrtitis, pain, physical therapy, microbiota

Osteoarthritis (OA) is not simply a matter of mechanical damage to articular cartilage, and in the past 20 years it has become clear that several risk factors are involved in the manifestation of the OA phenotype [1]. Abnormal joint biomechanics, age, gender, injuries, obesity, genetic, stress and psychological factors are related to the presence of symptoms in people with OA, however there is still a discrepancy between pain and structural damage [2,3]. This gap between OA-related pain and structural damage is usually explained by the propensity of some patients with $\mathrm{OA}$ to develop sensitization.

The central sensitization is a modification of the central nociceptive circuits that intensify the pain experience during various states of peripheral tissue injury. However, recent evidence suggests that OA-related pain cannot solely be attributed to peripheral and central nociception, and several studies have been conducted in order to better establish how chemical pathways, and cognitive and emotional factors are involved in this maladaptive state [4]. Recent theories support the importance of the interaction between brain and gut in pain perception thus considering the gut microbiota as a possible key factor in pain processing.

Based on preclinical studies, it is hypothesized that central (and peripheral) nervous system function could be mediated via a gut-brain axis [5]. The gut microbiota interacts with the host immune, metabolic, endocrine and nervous systems. For example, cortical microglia maturation and function are regulated in part through microbiota metabolites and gut microbiota metabolites can both increase and decrease excitability of neurons in the dorsal horn through modulation of immune derived inflammation [6]. Such findings suggest both mechanisms for development and prolonging of pain, as well as targets for disease treatment and health promotion [7].

In addition, several common risk factors for OA-related pain interact with gut microbiota. Moreover, gut microbiota is a contributor of drug metabolism, bioavailability and may modify the response to pain medications used to manage OArelated symptoms [8]. The evidence for the association between OA-related pain and gut microbiota is emerging and, in fact, the hypothesis that modifying the microbial environment by means of microbiota manipulation may help to improve symptoms in patients with OA-related pain, is already under investigation [9].

OA-related pain is therefore a current problem for which researchers are still trying to find effective methods of treatment even if this complex multifactorial pain state is not yet well understood. Conservative treatment for OA-related pain has traditionally focused on enhancing patients' functional capacities before surgery and improving postoperative outcome [10]. Nowadays, comprehensive conservative treatment, beyond the emphasis on function, is useful in the treatment of people with OA-related pain.

OA-related pain management needs a multidisciplinary approach involving various treatment options including nonpharmacological and pharmacological ones. Nonpharmacological treatment encompasses manual therapy, strengthening and range-of-motion exercises, joint-protection education, heat modalities, orthoses, pain neuroscience education about what contributes to the pain experience, and symptom control techniques including provision of a home exercise program. While no standard non-pharmacological treatment program is reported in the literature, efforts are ongoing to determine effective patient phenotyping (and endotyping) subgroups to guide treatment that is matched to the personalized characteristics of the patient with OA [11].

The standard pharmacological treatment includes agents for pain control and inflammation and the group of the symptomatic slow acting drugs for OA such as glucosamine sulfate, chondroitin sulfate, diacerein administered orally and intraarticular hyaluronic acid. In addition, a number of small 
studies suggested the therapeutic efficacy of hydroxychloroquine in patients with $\mathrm{OA}$, but the results are contradictory. Pharmacologic treatments have been clinically used for specific OA phenotypes, however a recent systematic review concluded that uncertainty surrounds the estimates of medication effect size for changes in knee OA pain for all comparisons with placebo [12] raising doubt in the effectiveness of these medications. Another important consideration related to drug consumption in patients with $O A$ related pain is associated adverse events involving the renal, gastrointestinal, cardiovascular, and central nervous system [13].

Besides these pharmacological and nonpharmacological treatments, there are also surgical interventions, which are considered in patients who do not respond to the conservative treatments. Due to the increase in average life expectancy, there has been a growth in the demand for surgical interventions, which has produced a growth in the costs associated with OA-related pain [15]. Considering that up to $30 \%$ of patients are dissatisfied after joint replacement surgery, a cohort study investigated the relation between severity of radiographic $\mathrm{OA}$ and the recovery prognosis in physical function after surgery. The study established that patients with similar levels of OA-related bodily pain, patients with severe radiographic OA had a higher odds of a relevant improvement in physical function and general health [14] than people with mild OA.

OA-related pain remains a poorly managed problem [16]. All non-pharmacological treatments are mostly minor variations on those early physical therapy or orthoses methods. Pharmacological intervention is principally targeted on improving pain symptoms, but no drug can effectively slow the disease progression. The exact role of the gut microbiota in the pathophysiology of OA remains under investigation. Lastly, surgical interventions aimed to remove structural damage, are expensive and improvement in OA-related pain is uncertain for most people.

Given the low number of high-quality studies related to OArelated pain treatment, how do clinicians know which conservative or non-conservative procedure should be chosen? We need clinical evidence that can be implemented into clinical practice, through randomized controlled studies that use consistent non-pharmacological treatments, matched to patients' OA phenotype. Manipulation of the gut microbiome could be a potential novel intervention to tackle or prevent OA-related pain. Education and lifestyle advice regarding the disease are the basis for self-management of chronic conditions, including pain. The number of people affected by $O A$ combined with the lack of healing treatments and the side effects of many pharmacological pain treatments, makes clear that more research in this field is urgently needed.

Author contributions: PP, MDB and JHV were responsible for the concept and design of the study. All authors drafted the manuscript and contributed to the interpretation of the data for the work. All authors have read and approved the final manuscript.

Funding: No funding source is reported for this study.

Declaration of interest: The authors no have conflict of interests.

\section{REFERENCES}

1. Barnett R. Osteoarthritis. Lancet Lond Engl. 2018 19;391(10134):1985. https://doi.org/10.1016/S0140-6736 (18) $31064-X$

2. Villafañe JH, Pedersini P, Bertozzi L, Drago L, FernandezCarnero J, Bishop MD, et al. Exploring the relationship between chronic pain and cortisol levels in subjects with osteoarthritis: results from a systematic review of the literature. Osteoarthritis Cartilage. 2020 May;28(5):572-80. https://doi.org/10.1016/j.joca.2020.02.836 PMid:32156623

3. Villafañe $J H$, Pedersini $P$, Berjano P. Epigenetics in Osteoarthritis Related Pain: An Update. Arch Rheumatol. 2020 Sep 1;35(3):456-7. https://doi.org/10.46497/Arch Rheumatol.2020.7663 PMid:33458673 PMCid:PMC7788648

4. Pedersini P, Negrini S, Cantero-Tellez R, Bishop MD, Villafañe JH. Pressure algometry and palpation of the upper limb peripheral nervous system in subjects with hand osteoarthritis are repeatable and suggest central changes. J Hand Ther Off J Am Soc Hand Ther. 2020 Mar;33(1):103-11. https://doi.org/10.1016/j.jht.2018.06.003 PMid:30679091

5. Nijs J, Tumkaya Yilmaz S, Elma Ö, Tatta J, Mullie P, Vanderweeën L, et al. Nutritional intervention in chronic pain: an innovative way of targeting central nervous system sensitization? Expert Opin Ther Targets. 2020 Jun 28;1-11. https://doi.org/10.1080/14728222.2020.1784142 PMid:32567396

6. Abdel-Haq R, Schlachetzki JCM, Glass CK, Mazmanian SK. Microbiome-microglia connections via the gut-brain axis. J Exp Med. 2019 07;216(1):41-59. https://doi.org/10.1084/ jem.20180794 PMid:30385457 PMCid:PMC6314531

7. Pedersini P, Turroni S, Villafañe JH. Gut microbiota and physical activity: Is there an evidence-based link? Sci Total Environ. 2020 Jul 20;727:138648. https://doi.org/10.1016/ j.scitotenv.2020.138648 PMid:32498183

8. Biver E, Berenbaum F, Valdes AM, Araujo de Carvalho I, Bindels LB, Brandi ML, et al. Gut microbiota and osteoarthritis management: An expert consensus of the European society for clinical and economic aspects of osteoporosis, osteoarthritis and musculoskeletal diseases (ESCEO). Ageing Res Rev. 2019;55:100946. https://doi.org/ 10.1016/j.arr.2019.100946 PMid:31437484

9. Villafañe $\mathrm{JH}$, Drago L. What is the site of pain osteoarthritis? A triple gut-brain-joint microbioma axis. Clin Exp Rheumatol. 2019 Dec;37 Suppl 122(6):20-1.

10. Pedersini P, Valdes K, Cantero-Tellez R, Cleland JA, Bishop MD, Villafañe JH. Effects of Neurodynamic Mobilizations on Pain Hypersensitivity in Patients with Hand Osteoarthritis Compared to Robotic Assisted Mobilization: A Randomized Controlled Trial. Arthritis Care Res. 2021 Feb;73(2):232-9. https://doi.org/10.1002/acr.24103 PMid:31675184

11. Mobasheri A, Saarakkala S, Finnilä M, Karsdal MA, BayJensen A-C, van Spil WE. Recent advances in understanding the phenotypes of osteoarthritis. F1000Research. 2019;8. https://doi.org/10.12688/f1000research.20575.1

PMid:31885861 PMCid:PMC6913225 
12. Gregori D, Giacovelli G, Minto C, Barbetta B, Gualtieri F, Azzolina D, et al. Association of Pharmacological Treatments With Long-term Pain Control in Patients With Knee Osteoarthritis: A Systematic Review and Metaanalysis. JAMA. 2018 25;320(24):2564-79. https://doi.org/ 10.1001/jama.2018.19319 PMid:30575881 PMCid: PMC6583519

13. Tragulpiankit $\mathrm{P}$, Chulavatnatol $\mathrm{S}$, Rerkpattanapipat $\mathrm{T}$, Janwityanujit S, Somjarit S, Sirikhedgon U. Adverse drug events in rheumatoid arthritis and osteoarthritis ambulatory patients. Int J Rheum Dis. 2012 Jun;15(3):31521. https://doi.org/10.1111/j.1756-185X.2012.01716.x PMid: 22709494

14. Keurentjes JC, Fiocco M, So-Osman C, Onstenk R, Koopman-Van Gemert AWMM, Pöll RG, et al. Patients with severe radiographic osteoarthritis have a better prognosis in physical functioning after hip and knee replacement: a cohort-study. PloS One. 2013;8(4):e59500. https://doi.org/ 10.1371/journal.pone.0059500 PMid:23573200 PMCid: PMC3616074
15. Kamaruzaman $\mathrm{H}$, Kinghorn $\mathrm{P}$, Oppong R. Costeffectiveness of surgical interventions for the management of osteoarthritis: a systematic review of the literature. BMC Musculoskelet Disord. 2017 May 10;18(1):183. https://doi.org/10.1186/s12891-017-1540-2 PMid:28486957 PMCid:PMC5424321

16. Villafañe $J H$, Valdes $K$, Pedersini $P$, Berjano $P$. Osteoarthritis: a call for research on central pain mechanism and personalized prevention strategies. Clin Rheumatol. 2019 Feb;38(2):583-4. https://doi.org/10.1007/ s10067-018-4270-4 PMid:30128914 